\title{
Aspectos fenológicos, ecológicos e de produtividade do umari (Poraqueiba sericea Tulasne)
}

\author{
Martha de Aguiar Falcão $\left(^{2}\right)$ \\ Eduardo Lleras $\left({ }^{3}\right)$
}

\begin{abstract}
Resumo
Foram estudados aspectos da fenologia, ecologia e produtividade do Umari (Poraqueiba sericea Tulasne). Os dados fenológicos indicam que, na região de $\mathrm{Ma}$ naus, a espécie floresce na época de menor precipitação pluviométrica (junho a outubro), com a safra na época de maiores chuvas (janeiro a março). Foram observadas 21 espécies de insetos visitando a espécie. das quais 10 , todas da familia Apidae, apresentaram quantidades significativas de pólen, o que sugere não existir um polinizador especifico e sim um sindrome de polinizaçāo. O número de flores foi muito alto para todas as 10 árvores estudadas, variando entre $13.000 \mathrm{e}$ 82.000 por árvore, com taxa de formação de frutos relativamente baixa (entre 4 e $9 \%$ ). Ainda se pode pensar na possibilidade de a baixa taxa de formação de frutos ser devida à pouca efetividade de polinização; há uma correlação surpreendentemente alta entre o número de flores e outros parâmetros de produção tais como números de frutos imaturos $\left(r=0,987^{\circ *}\right)$, números de frutos maduros $\left(r=0,989^{* *}\right)$ e peso da safra $\left(\mathrm{r}=0,98^{* *}\right)$, o que sugere que há outros fatores que podem estar desempenhando papéis muito importantes na determinação da produção das árvores (safra). Parece que o número de flores está intimamente correlato com a capacidade energética da árvore para produ. zir um peso determinado de frutos, sugerindo um controle endógeno de números de frutos formados e frutos abortados de maneira a manter um certo peso e número de frutos que atingem maturação.
\end{abstract}

\section{INTRODUÇÃo}

Com o progresso da tecnologia industrial e o aumento da população, a quantidade e produtividade das espécies frutíferas têm despertado grande interesse aos fruticultores do mundo.

No Brasil, encontram-se inúmeros trabathos realizados com a cultura de plantas frutiferas, no entanto, na Amazônia, só agora come- çam a ser desenvolvidos trabaihos nesta linha de pesquisa.

A região amazônica, embora ofereça uma grande diversidade de espécies frutiferas nativas, apresenta uma série de problemas quanto à cultura das mesmas, dada, em parte, a falta de estudos básicos.

Dentre os trabalhos sobre a cultura de plantas que estão sendo realizados na região de Manaus, encontram-se os de Clement et al. (1977) que estão realizando uma série de experimentos sobre o melhoramento genético e banco de germoplasma de algumas espécies frutiferas, especialmente de Mapati e Sapota; Pahlen (1978) iniciou experiências sobre o meIhoramento genético e cultura de algumas hortaliças e plantas frutíferas, as quais estão sendo concluídas por Clement. Gondim (1978) estuclou alguns aspectos da biologia reprodutiva do guaraná. Kerr et al. (1980) apresentaram dados sobre as práticas de seleção de plantas cultivadas pelos índios amazônicos.

Este é o primeiro de uma série de trabaIhos de fruteiras nativas ou cultivadas na Amazônia, nos quais se apresentam dados fenológicos, ecológicos e de produtividade visando a contribuir para a fruticultura, na região.

\section{MATERIAL E MÉTODOS}

Para efeitos de comparação entre dois ha. bitats, foram estudadas seis árvores da Fazenda NAF-6, Estrada Manaus-Caracarai Km 14 e quatro no Sítio Rosa de Maio, Estrada ManausItacoatiara $\mathrm{Km} \mathrm{8.} \mathrm{As} \mathrm{observações} \mathrm{de} \mathrm{campo}$ foram realizadas entre fevereiro de 1977 e agosto de 1978.

(1) - Parte deste trabalho foi extraída da Tese para obtenção do grau de Mestre em Ciências Biológicas pelo primeiro autor - INPA/FUA.

(2) - Fundação Universidade do Amazonas, Manaus.

(3) - Instituto Nacional de Pesquisas da Amazônia. Manaus. 
Foram coletadas amostras-testemunhas as quais foram depositadas no herbário do INPA sob o seguinte número: Poraqueiba sericea, col. Martha Falcão no $13, n .^{\circ}$ do Herbário 40937.

As observações de campo foram realizadas semanaimente. As datas estimadas quanto ao início e ao término dos fenômenos fenológicos tềm assim aproximação de \pm 6 dias .

Durante o período de floração, em cada árvore foram escolhidos 3 galhos, ao acaso, nos quais se fez a contagem das inflorescências e flores. Com a finalidade de estimar-se a quantidacie de inflorescências e flores produzidas pela árvore, foram contados todos os galhos.

As flores foram dissecadas e comparadas com a descrição, feita por Prance \& Silva (1975).

A fim de ter-se uma idéia de que as flores eram ou não autofecundadas, foram colocados envoltórios de filó de malhas milimétricas ou de morim em 10 infiorescências de cada árvore, dando um total de 100 envoltórios para a espécie.

Foi feito o estudo do pólen encontrado nas patas dos insetos com a finalidade de fazer-se uma comparação com o pólen da espécie visitada. Nos dois casos, o método usado na preparação do pólen foi o da acetólise (Erdtman, 1960 ), seguido da montagem de grãos em gelatina glicerinada.

Para determinarem-se os possíveis polini. zadores de cada espécie, todos os insetos que visitavam as flores foram coletados, acondicio. nados e identificados pelo Dr. Norman Penny do Departamento de Entomologia do INPA, Dr. Warwick Kerr $\in$ Dr. João Camargo da Faculdade de Medicina de Ribeirão Preto.

Para estabelecer-se uma correlação entre a freqüência dos insetos nas árvores e a quantidade de pólen que eles carregam, foi feita a contagem padrão de 1.000 grãos de pólen por amostra.

No período de frutificação, as contagens dos frutos foram feitas nos mesmos gaihos em que foram contadas as inflorescências e flores. Tanto os frutos imaturos quanto os maduros que permaneciam nos galhos ou caídos embaixo de cada árvore foram contados com o obje- tivo de caícular-se a média dos frutos perdidos e da safra de cada espécie.

Foram pesados 500 frutos, ou seja, 50 frutos de cada árvore. Dos frutos submetidos à pesagem, foram retiradas as sementes, polpas e cascas, as quais foram pesadas, sendo que as sementes foram também contadas. Para as pesagens obtidas foi utilizada balança de precisão.

Foram feitas medidas do fuste, do diâmetro e da copa das árvores em estudo a fim de fazer-se uma correlação entre a idade e a produtividade dessas árvores.

Todos os resultados obtidos foram submetidos a diversos cálculos estatísticos, como: média aritmética, desvio-padrão, erro padrão da média, variância, coeficiente de variação, teste " $T$ ", teste d'Agostini, curtose, regressão linear e $X^{2}$.

As descrições botânicas das espécies foram baseadas nos trabalhos de Prance \& Silva (1975), Cavalcante (1976) e em observações pessoais.

\section{CONSIDERAÇÕES GERAIS}

O Umari, Poraqueiba sericea é conhecido botanicamente desde o século passado, tendo sido descrito por Tulasne em 1849 (cit. Englers, 1872). Segundo Le Cointe (1947) o seu nome tem origem indígena e é uma planta cultivada pelos silvícolas (Froes Apud Cavalcante \& Carvalho, 1971). Vários trabalhos foram publicados a seu respeito. Dentre os mais recentes, podem-se citar os de Altman et al. (1965b) que estudaram o óleo de seus frutos. Cavalcante \& Carvalho (1971) fizeram uma revisão taxonômica do gênero Poraqueiba. Carvalho (1971) estudou a sua morfologia polínica. Prance \& Silva (1975) e Cavalcante (1976) fizeram referências sobre os seus nomes vulgares, descrição botânica, habitat, distribuição geográfica, aspectos fenológicos e valor econômico.

\section{ASPECTOS BOTÂNICOS}

Nome científico: Poraqueiba sericea Tulasne (Fig. 1; a, b, c, d).

Nomes vulgares : Mary, Mari, Umari e Umaripreto.

Família : Icacinaceae. 

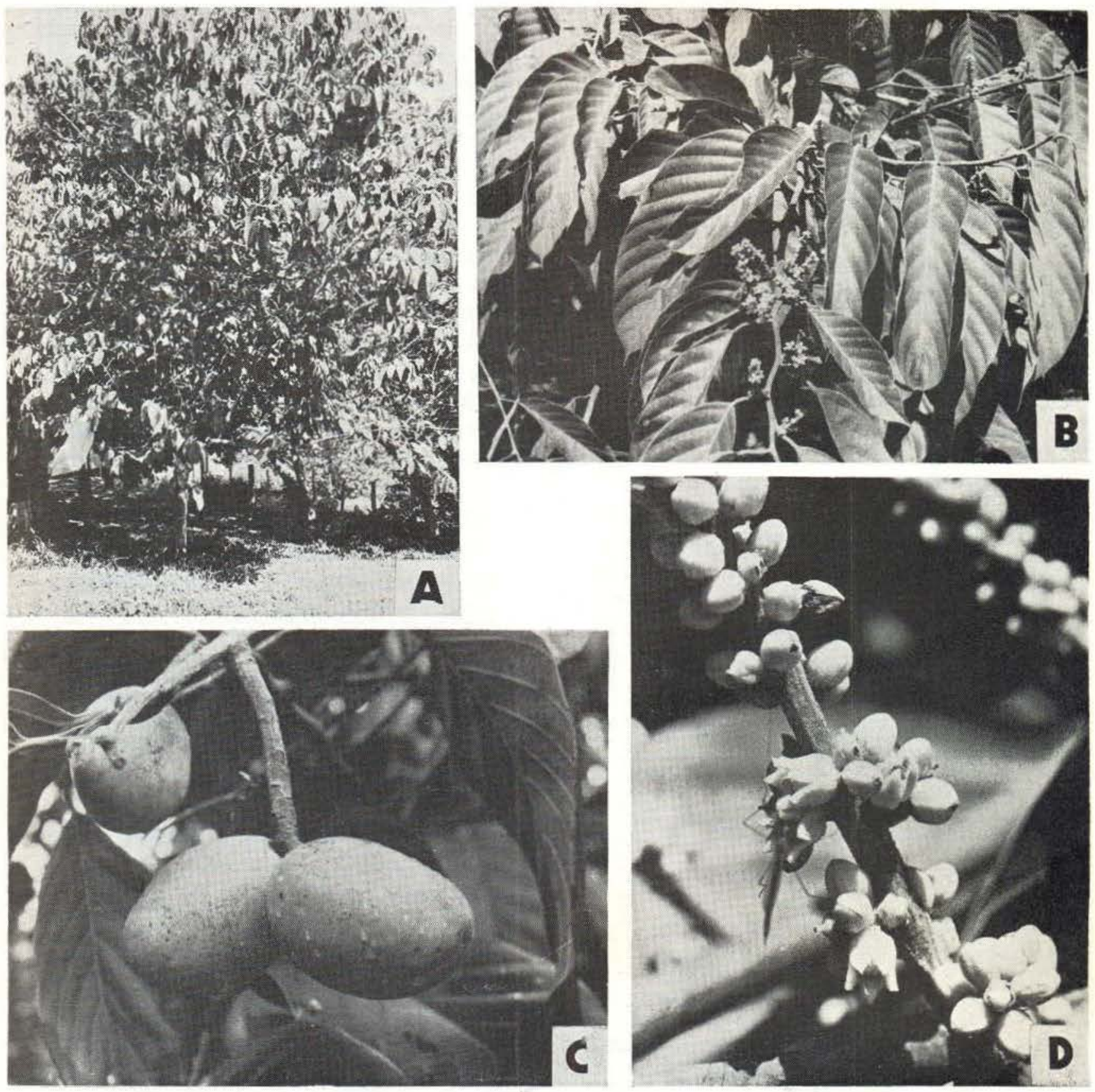

Fig. 1 - Poraqueiba sericea. A, aspecto geral da árvore; B, galho mostrando inflorescência; C, frutos quase maduros; D, detalhes de uma inflorescência.

Arvore de 8-12 m de altura, copa ampla e ramificada; folhas simples, alternas, pecioladas; lâmina coriácea elítico-ovada; margem inteira; ápice acuminado; base redonda, glabras na face superior; inflorescências em panículas terminais de $3-7 \mathrm{~cm}$ de comprimento; flores hermafroditas, sésseis, actinomorfas, diclamí. deas, lobos obtuso-ovados, densamente sericeos; receptáculo gíoboso; sépalas 5 , gamos- sépalas, lanceoladas; pétalas 5 , ovado-lanceoladas; estames 5; hipóginos; anteras rimosas longitidinalmente, dorsifixas; ovário súpero; óvulos anátropos; estilete terminal; fruto drupa ovado-oblongo; epicarpo fino amarelo, roxo-es curo, amarelo-esverdeado e amarelo-avermeIhado; mesocarpo duro lenhose, oval, com uma semente grande. 
DISTRIBUIÇÃO GEOGRÁFICA E HABITAT

No Brasil, Poraqueiba sericea ocorre no Es. tado do Amazonas (Alto rio Negro, cachoeiras Pari, Içana e Tunuí, rio Solimões desde Manaus até Tabatinga e Humaitá no rio Madeira) (Le Cointe, 1947; Fonseca, 1954; Prance \& Silva, 1975; Cavalcante, 1976) .

Atinge também países limítrofes, na Colômbia, em Letícia, e no Peru, no Departamento de Loreto (Fig. 2).

Encontra-se nas matas de terra firme.

Usos

Os frutos são comestíveis e produzem um óleo que é aproveitado no preparo do arroz cozido (Kerr, comunicação pessoal). A semente contém amido (Pesce, 1941), o qual é usado para engomar roupa. A madeira é empregada na inarcenaria e no fabrico de tamancos (Le Cointe, 1947; Prance \& Silva, 1975).
Até o presente momento, não se conhece nenhuma cultura comercial de umari, porém é largamente cultivado nos sítios e pomares de Manaus e seus arredores.

\section{CARACTERÍSTICAS QUÍMICAS}

A constituição química do umari tem sido estudada por diversos autores. Pesce (1941) verificou que o fruto contém $25 \%$ do seu peso representado por um óleo de cor amarelo-escura e que apresenta odor semelhante ao de avelã. Brest (Apud. Altman et al., 1965a) determinou as constantes químicas deste óleo, as quais são citadas a seguir:

Densidade ................ $\quad 0,9135$

Ponto de solidificação ........ $41^{\circ} \mathrm{C}$

Acidez em oléico .......... 21\%

Índice de saponificação ........ 196

Índice de iodo ............ 71,8

f́ndice de refração (n.D a $15^{\circ} \mathrm{C}$ ) .. $\quad 1,6485$

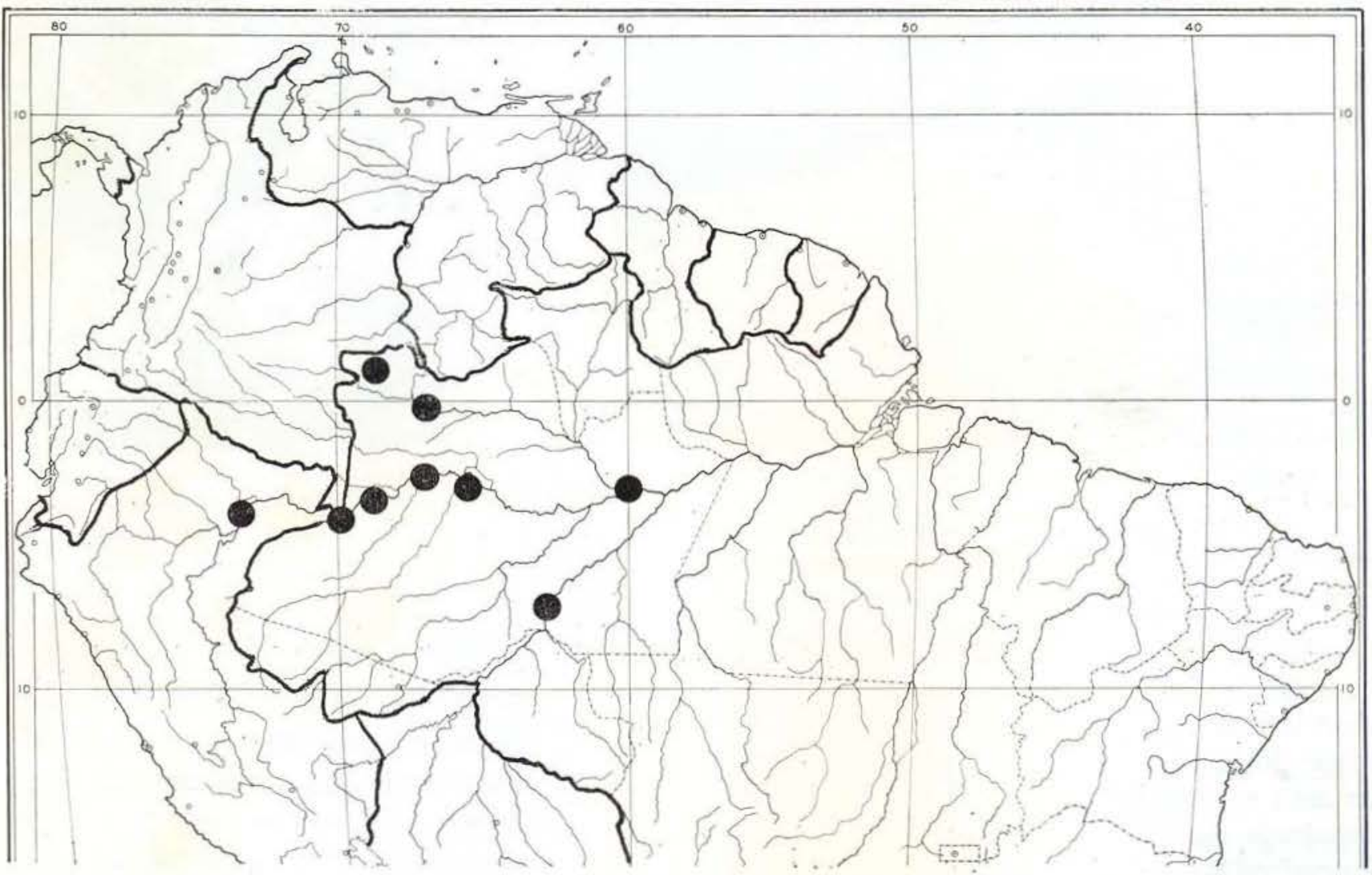

Fig. 2 - Distribuição geográfica conhecida de Poraqueiba sericea. 
Altman et al. (1965a,b) fizeram a análise química do umari-amarelo e do umari-roxo e consideram o umari-amarelo como Poraqueiba paraensis e o umari roxo como $P$. sericea. Howard (1942) verificou que os frutos de $P$. sericea apresentam cores variáveis, podendo ser desde amarelo até preto e que estas variações de cores não são correlatas com outras características, que permitam separar estas variantes como espécies diferentes. Deixou também claro que a distribuição de $P$. paraensis está limitada ao Estado do Pará, sendo examinado por Altman et al. $(1965 a, b)$ todo o material proveniente de Manaus, tanto de frutos amarelos quanto de roxos. Deve-se supor, então, tratar-se todos de $P$. sericea com frutos de cores diferentes. A seguir são apresentados os dados obtidos por Altman et al. (1965a).

A Tabela 1, além de indicar algumas diferenças interessantes entre os frutos amarelo e roxo, demonstra claramente que a maior parte do peso do umari atualmente aproveitado (casca e polpa comestível) está representada por gorduras. Ademais, a semente, que não é ainda aproveitada, contém um alto teor de amido.
Altman et al. (1965b) concluiram que o óleo tanto do umari-roxo como do amarelo, são semelhantes, o que apoia ainda mai.s a teoria de Howard (1942) que diz tratar-se de uma mesma espécie.

\section{Fenologia}

FLORAÇÃO

Durante o presente estudo, (1977-1978), a floração de Poraqueiba sericea ocorreu entre 28 de junho a 18 de outubro, o que amplia a época dada por Prance e Silva (1975). Ao levar-se em considerações os locais de estudo, observou-se que na fazenda NAF-6 na estrada Manaus-Caracaraí $\mathrm{Km} \mathrm{14}$, onde estão situadas as árvores de 1 a 6, a floração ocorreu aproximadamente entre 28 de junho a 21 de setem. bro, (') enquanto que no sítio Rosa de Maio, no $\mathrm{Km} 8$ da estrada Manaus-Itacoatiara (árvore de 7 a 10), o período de floração foi de 5 de agos. to a 18 de outubro. (Tabela $2-$ Fig. 3 ) .

TABELA 1 - Teor em \% de substâncias secas de Poraqueiba sericea (segundo Altman et al., 1965a).

\begin{tabular}{|c|c|c|c|c|c|c|}
\hline \multirow[b]{2}{*}{$\begin{array}{l}\text { Teor } \\
\text { em \% de } \\
\text { substância } \\
\text { seca }\end{array}$} & \multicolumn{3}{|c|}{ UMARI-AMARELO } & \multicolumn{3}{|c|}{ UMARI-ROXO } \\
\hline & $\begin{array}{c}\text { Casca + } \\
\text { polpa co- } \\
\text { mestivel }\end{array}$ & $\begin{array}{l}\text { Polpa } \\
\text { não co- } \\
\text { mestível }\end{array}$ & $\begin{array}{c}\text { Caroço } \\
\text { sem } \\
\text { casca }\end{array}$ & $\begin{array}{c}\text { Casca }+ \\
\text { polpa co- } \\
\text { mestível }\end{array}$ & $\begin{array}{c}\text { Polpa } \\
\text { não co- } \\
\text { mestível }\end{array}$ & $\begin{array}{c}\text { Caroço } \\
\text { sem } \\
\text { casca }\end{array}$ \\
\hline Proteínas & 4,46 & 2,98 & 4,53 & 2,90 & 2,72 & 5,20 \\
\hline Gorduras & 47,80 & 16,86 & 0,39 & 49,56 & 8,61 & 0,49 \\
\hline Amido & - & 15,43 & 63,80 & 9,56 & 11,52 & 62,84 \\
\hline Cinzas & 1,80 & 1,85 & 1,83 & 1,66 & 1,87 & 1,92 \\
\hline $\mathrm{CaO}$ & 0,16 & 0,23 & 0,10 & 0,13 & 0,22 & 0,14 \\
\hline
\end{tabular}

(1) - Sendo que as observações foram semanais, tødas as datas e períodos de observações têm aproximação de \pm 6 dias. 
TABELA 2 - Poraqueiba sericea. Dados fenológicos de 1977 a 1978.

\begin{tabular}{|c|c|c|c|c|c|c|c|c|c|c|}
\hline \multirow{3}{*}{ ESPECIFICAÇÃO } & \multicolumn{10}{|c|}{ DIAS - MESES } \\
\hline & \multicolumn{10}{|c|}{ A R VORES } \\
\hline & 01 & 02 & 03 & 04 & 05 & 06 & 07 & 08 & 09 & 10 \\
\hline Início da floração & 01.07 & 01.07 & 01.07 & 25.06 & 28.06 & 01.07 & 05.08 & 05.08 & 05.08 & 05.08 \\
\hline Maior floração & 05.08 & 05.08 & 05.08 & 05.08 & 05.08 & 05.08 & 21.09 & 21.09 & 21.09 & 21.09 \\
\hline Término da floração & 21.09 & 21.09 & 21.09 & 21.09 & 21.09 & 21.09 & 18.10 & 18.10 & 18.10 & 18.10 \\
\hline Período da floração & \multicolumn{3}{|c|}{01.07 a 21.09} & \multicolumn{2}{|c|}{$\begin{array}{c}28.06 \\
a \\
21.09\end{array}$} & $\begin{array}{c}01.07 \\
a \\
21.09\end{array}$ & \multicolumn{4}{|c|}{05.06 a 18.10} \\
\hline Início da frutificação & 25.08 & 25.08 & 25.08 & 22.07 & 22.07 & 25.08 & 12.10 & 12.10 & 12.10 & 12.10 \\
\hline Frutos maduros (safra) & $\begin{array}{c}10.01 \\
a \\
26.03\end{array}$ & $\begin{array}{c}10.01 \\
a \\
26.03\end{array}$ & $\begin{array}{c}10.01 \\
a \\
26.03\end{array}$ & $\begin{array}{c}02.12 \\
a \\
22.02\end{array}$ & $\begin{array}{c}02.12 \\
a \\
22.02\end{array}$ & $\begin{array}{c}10.01 \\
a \\
26.03\end{array}$ & $\begin{array}{c}16.01 \\
a \\
08.03\end{array}$ & $\begin{array}{c}16.01 \\
a \\
08.03\end{array}$ & $\begin{array}{c}16.01 \\
a \\
08.03\end{array}$ & $\begin{array}{c}16.01 \\
a \\
08.03\end{array}$ \\
\hline Período da frutificação & & 08 a 2 & & & $\begin{array}{l}.07 \\
02\end{array}$ & $\begin{array}{c}25.08 \\
a \\
26.03\end{array}$ & & 12.10 & 08.03 & \\
\hline Mudança foliar & \multicolumn{10}{|c|}{02.03 a 30.06} \\
\hline Localização das árvores & & & Fazenda & NAF-6 & & & & Rosa d & Maio & \\
\hline
\end{tabular}

A floração durou entre 75 (árvores 7 a 10) e 86 dias (árvores 4 e 5). Na fazenda NAF-6, com árvores de aproximadamente 4 anos de idade, a floração foi relativamente mais longa que no Rosa de Maio com árvores mais velhas (aprox. 12 anos). Houve uma defasagem de 36 a 38 dias entre o início da floração entre as duas localidades sendo que o início da floração das árvores no Rosa de Maio, coincidiu com a data de maior floração da fazenda NAF-6. As árvores mais novas (NAF-6) atingiram a maior floração entre os 36 e 38 dias do início da mesma, sendo que as árvores mais velhas (Rosa de Maio) só alcançaram a maior flora- ção aos 48 dias do início da mesma, coincidindo com o final da floração das árvores da NAF-6.

$\mathrm{Na}$ fig. 3, pode comprovar-se que, em termos gerais, a floração, nas duas áreas de estudo, coincide basicamente com o período de menor precipitação pluviométrica para a área de Manaus. Face à falta de dados microclimatológicos locais, nas duas áreas de estudo, é impossível determinar se de fato, a defasagem tanto de início e fim de floração quanto de duração da mesma, é devida a condições microclimatológicas locais, idade das árvores ou outros fatores. 


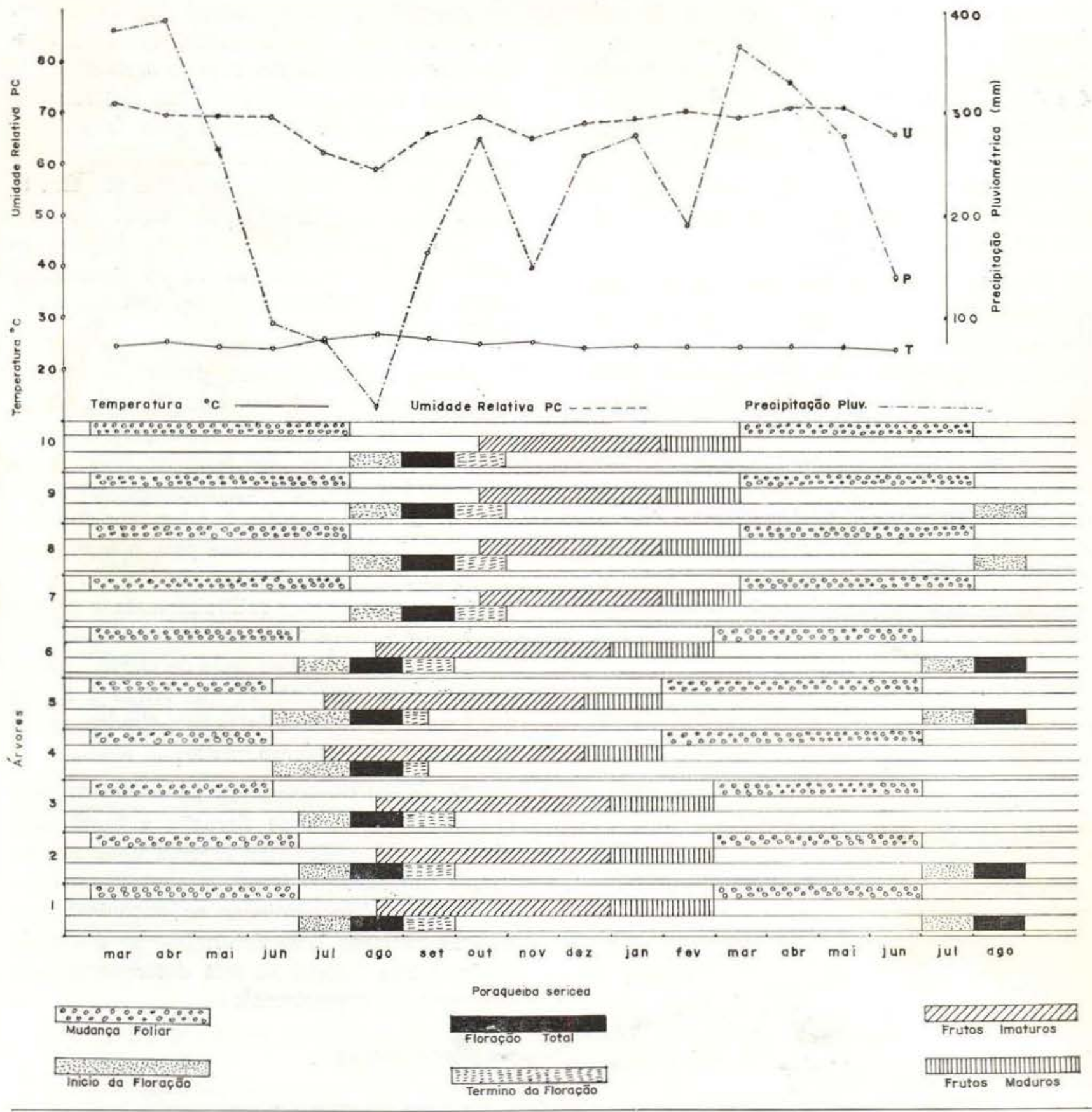

Fig. 3 - Poraqueiba sericea. Quadro geral de floração, frutificação, produção e queda de folhas. Acima, dados climatológicos para a área de Manaus; abaixo, dados fenológicos. (Dados climatológicos de Ribeiro, 1977).

A abertura das flores occrre, na maioria dos casos, na parte da manhã, sendo notório o fato de poucas flores abrirem em dias nublados ao comparar-se com dias ensolarados. Durante a floração, as flores abrem gradativamente nas inflorescências, fazendo com que a formação de frutos também seja gradual em cada inflorescência.

\section{FRUTIFICAÇÃo}

A frutificação foi observada pela primeira vez no dia 22 de julho de 1977 (árvore 4 e 5) e terminou no dia 26 de março do ano seguinte (árvores 1, 2, 3 e 6), dados estes que não estão de acordo com o anotado por Prance \& Silva (1975) que indicaram a frutificação entre 
novembro e janeiro. Aqui, como no caso da floração, encontram-se basicamente 3 grupos de árvores; as árvores 1, 2, 3 e 6; as árvores 4 e 5 e as árvores 7 a 10. A tabela 3 indica a duração em dias entre os principais eventos ocorridos durante a frutificação $\left({ }^{2}\right)$. Entende-se aqui por início de frutificação o dia em que foi observada pela primeira vez a ocorrência de frutos verdes.

É notório o fato de existirem algumas coincidências entre as árvores $1,2,3 \mathrm{e} 6 \mathrm{e}$ as árvores 7 a 10, ainda se săo de locais bem diferentes; temos, então, que os períodos de início de floração ao início de frutificação e início de frutificação à máxima floração são mais semeIhantes entre si que eles como os períodos respectivos para as árvores 4 e 5 . Isto pode, em parte, dever-se ao fato de que estas árvores não receberam cuidados ou adubação especial, sendo, que as árvores 4 e 5 formam parte de um pomar que recebe adubação e tratamento especiais.

TABELA 3 - Poraqueiba sericea Duração em dias dos principais eventos durante a frutificação.

\begin{tabular}{l|c|c|c}
\cline { 2 - 3 } & & DURAÇÃO EM DIAS \\
\hline & $1,2,3,6$ & 4,5 & $7,8,9,10$ \\
\hline EVENTOS & 50 & 25 & 69 \\
\hline $\begin{array}{l}\text { Inicio de floração a } \\
\text { inicio de frutificação }\end{array}$ & $21+$ & 15 & $23+$ \\
\hline $\begin{array}{l}\text { Maior floração a } \\
\text { inicio de frutificação }\end{array}$ & 28 & 62 & 7 \\
\hline $\begin{array}{l}\text { Final de floração a } \\
\text { inicio de frutificação }\end{array}$ & 83 & 86 & 75 \\
\hline $\begin{array}{l}\text { Duração da floração } \\
\text { Duração da frutificação }\end{array}$ & 214 & 226 & 148 \\
\hline $\begin{array}{l}\text { Inicio de frutificação } \\
\text { a início da safra }\end{array}$ & 139 & 153 & 97 \\
\hline \begin{tabular}{l} 
Duração da safra \\
\hline
\end{tabular} & 76 & 63 & 53 \\
\hline
\end{tabular}

Ao mesmo tempo, nota-se que as árvores $1,2,3$ e 6 estão bem ajustadas quanto à duração total da frutificação com as árvores 4 e 5 , diferindo consideravelmente das árvores 7 a 10. Isto pode ser explicado pelo fato de as primeiras terem quatro anos de idade, sendo que as do local Rosa de Maio ( 7 a 10) têm 12 anos. Este feriomeno parece estar correlato com a idade e não com o tamanho das árvores sendo que como pode ver-se na tabela 4 , a seguir, não há correlação entre tamanho e duração da frutificação.

Desde o ponto de vista prático, as árvores mais velhas ( 7 a 10 , no sítio Rosa de Maio) apresentaram uma série de vantagens sobre as árvores mais novas; em primeiro lugar, a duração da frutificação é consideravelmente menor. Além disto, a safra é de menor duração, o que é de grande interesse para o fruticultor. sendo que o Umari não pode ser tirado da árvore para amadurecer artificialmente e os frutos têm que ser apanhados dia a dia do chão, ao cair. A grande quantidade de Umari amargo ou sem sabor encontrado nas feiras é devida precisamente ao fato de serem tirados da árvore antes do amadurecimento.

Os dados apresentados na tabela 3 sugerem que o período de floração e frutificação são mais compactos nas árvores mais velhas. Porém, para afirmar isto, de maneira categórica, é necessário continuar as pesquisas, nas árvores menores, para determinar se é a idade e não outros fatores os que determinam esta diferença de comprimento.

\section{MUDANÇA FOLIAR}

A mudança foliar de $P$. sericea ocorreu no período de 2 de março a 30 de junho (Tab. 2; Fig. 3) .

Nas árvores 4 e 5 , à medida que ocorria a mudança foliar, ocorria também a floração, enquanto nas demais árvores, a floração, só teve início quando estas se apresentavam totalmen. te de folhas novas.

(2) - Todas as observações têm aproximação de \pm 6 dias sendo que foram feitas semanalmente. Não deve supor-se uma sincronia total entre árvores que apresentam as mesmas datas e duração, porém os eventos anotados ocorreram na mesma semana. 
TABELA 4 - Poraqueiba sericea. Tamanho das árvores estudadas considerando diâmetro do fuste à altura do peito, altura da mesma, altura total das árvores e idade das mesmas.

\begin{tabular}{|c|c|c|c|c|c|}
\hline LOCAIS & ARVORES & $\begin{array}{c}\text { DIÂMETRO } \\
(\mathrm{cm})\end{array}$ & $\begin{array}{l}\text { ALTURA DO } \\
\text { FUSTE (m) }\end{array}$ & $\begin{array}{l}\text { ALTURA TOTAL } \\
(\mathrm{m})\end{array}$ & $\begin{array}{l}\text { IDADE } \\
\text { (anos) }\end{array}$ \\
\hline \multirow{6}{*}{ Fazenda NAF-6 } & 1 & 10 & 1,40 & 3,90 & 4 \\
\hline & 2 & 8 & 1,30 & 3,30 & 4 \\
\hline & 3 & 10 & 0,85 & 2,85 & 4 \\
\hline & 4 & 15 & 0.75 & 2,75 & 4 \\
\hline & 5 & 8 & 1,50 & 4,00 & 4 \\
\hline & 6 & 6 & 1,10 & 3,10 & 4 \\
\hline \multirow{4}{*}{$\begin{array}{c}\text { Sítio } \\
\text { Rosa de Maio }\end{array}$} & 7 & 8 & 0,90 & 2,80 & 12 \\
\hline & 8 & 32 & 1,20 & 9,20 & 12 \\
\hline & 9 & 25 & 2,00 & 9,00 & 12 \\
\hline & 10 & 24 & 2,00 & 8,00 & 12 \\
\hline
\end{tabular}

\section{INSETOS VISITANTES}

Durante as observações dos insetos que visitam as flores de $P$. sericea, foram capturados 21 espécies pertencentes a diferentes ordens (Tab. 5; Fig. 4).

A ordem Hymenoptera foi a mais representada com um total de 15 espécies distribuídas em 8 familias enquanto que as ordens Coleoptera e Hemiptera foram as menos representadas com uma espécie para cada. As ordens Diptera e Lepidoptera foram representadas por um número de espécies intermediário ao acima citado, ou seja, foram representadas por duas espécies, respectivamente (Tab. 5).

Quanto à preferência de horário de visitas dos insetos coletados, verificou-se que as espécies de ordem Hymenoptera freqüentam as flores pela parte da manhã, com exceção de uma vespa, da família Pompilidae que também realiza as suas visitas pela parte da tarde. As espécies das ordens Diptera, Hemiptera e Lepidoptera freqüentam as flores em torno do horário das 9 horas às 14 horas. Foi observado que a espécie de ordem Coleoptera freqüenta as árvores de $P$. sericea quando estas se encontram no período de frutificação com a finalidade única de predar os frutos maduros. Pelo fato de terem sido encontrados inúmeros insetos desta espécie estragando os frutos, supõe- se que estes acarretam problemas econômicos de grande importância.

Observou-se também que a intensidade de visita dos insetos é proporcional à abertura das flores, ou seja, nos dias ensolarados, a freqüência destes é maior que nos dias nublados e chuvosos.

Quanto aos resultados obtidos da comparação do pólen de $P$. sericea com o póien encontrado nos insetos que visitam as flores. verificou-se que nas amostras das espécies Paratrigona (Aparatrigona) impunctata (Ducke), Trigona (Trigona) cilipes cilipes (Fabricius) e Trigona (Trigona) sp. existiam grande quantidade de grãos de pólen somente de $P$. sericea, enquanto nas lâminas das demais espécies da ordem Hymenoptera, encontrou-se uma variedade muito grande de grãos de pólen de outras espécies vegetais.

Nas amostras das espécies das ordens Diptera, Hemiptera e Lepidoptera, não foi en contrado nenhum grão de pólen (Tab. 5) .

Pode concluir-se com certa segurança que a polinizaçăo de $P$. sericea está sendo feita por várias espécies de abelhas, não havendo portanto. especificidade total de polinizador.

Como foi discutido anteriormente, a baixa formação de frutos pode estar sendo limitada pela disponibilidade de polinizadores. Todavia, mais pesquisas são necessárias para poder firmar-se este fenômeno categoricamente. 


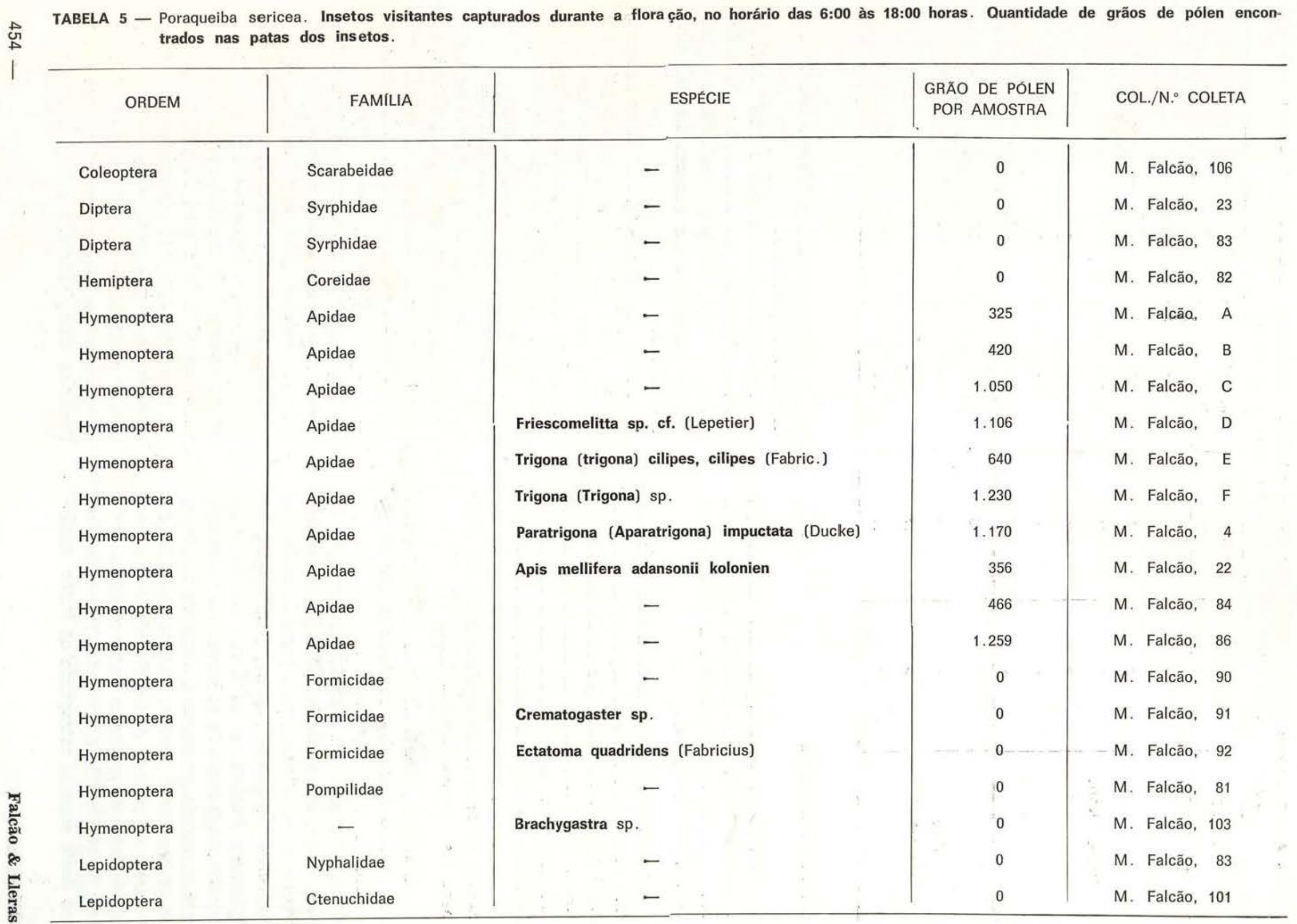



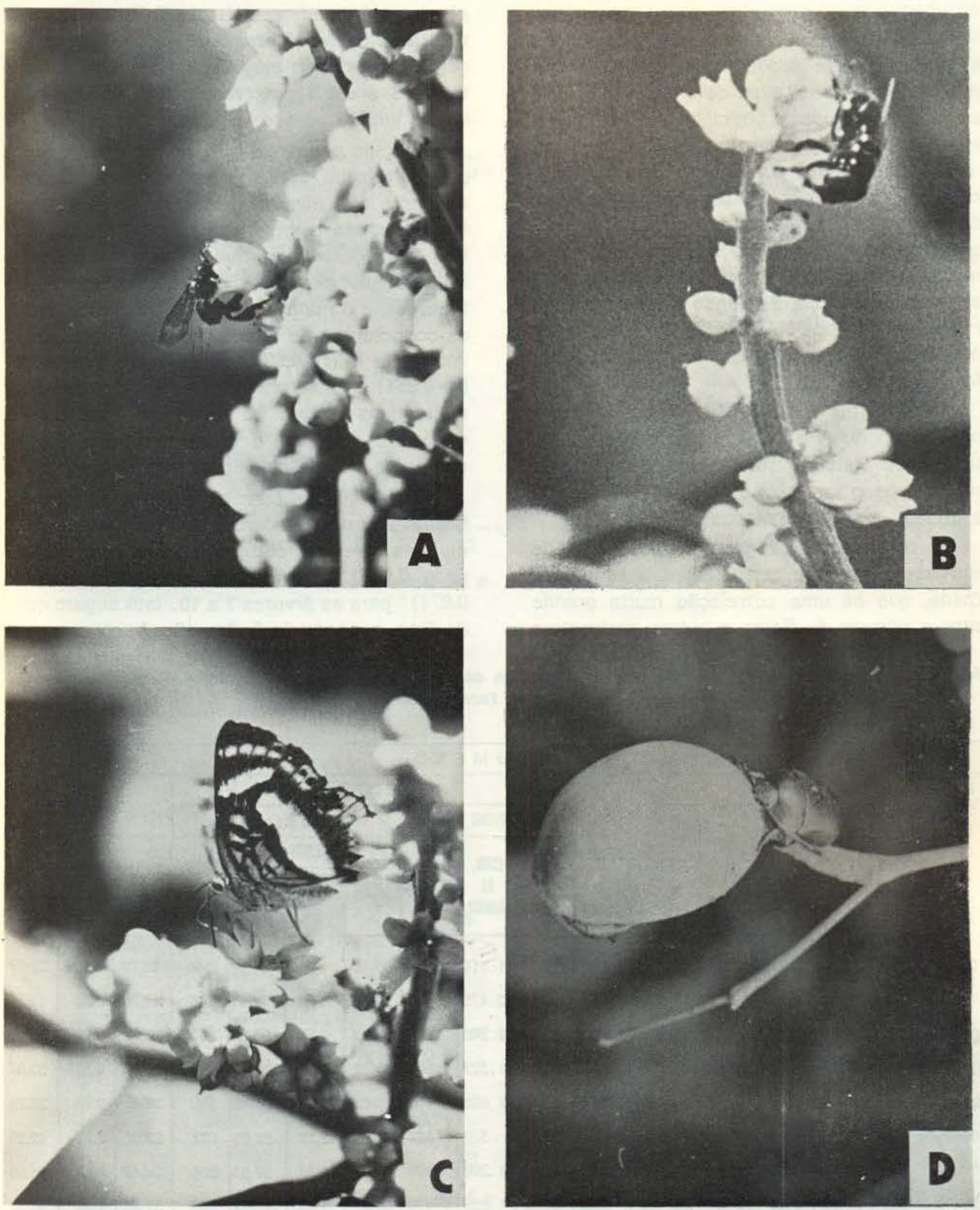

Fig. 4 - - Insetos visitantes em Poraqueiba sericea. A, Trigona Sp.; B. Diptera, Syrphidae; C, Lepidoptera. Nymphalidae; Coleoptera, Scarabeidae. 


\section{ANÁLISE DE PRODUÇÃo}

$\mathrm{Na}$ tabela 6 , encontram-se as médias dos dados básicos de produção de flores, frutos imaturos e maduros, peso de safra e peso das sementes entre outros. Inicialmente pensou-se existirem três grupos básicos de árvores (1, 2, 3 e $6 ; 4$ e $5 ; 7$ a 10) como já foi discutido para floração e frutificação. Feitas algumas análises básicas, porém, encontrou-se que o comportamento quanto à produção das árvores 4 e 5 enquadravam-se bem com o comportamento das árvores 1, 2, 3 e 6 . Sendo assim, todas as árvores da Fazenda NAF-6 (1 a 6) foram agrupadas e comparadas com as do Sítio Rosa de Maio (7 a 10).

Foram feitas análises de regressão linear comparando número de flores produzidas com número de frutos verdes, número de frutos maduros, peso da safra e frutos perdidos. Os resultados são apresentados na figura 5 .

Os resultados da regressão são de grande interesse sendo que estabelecem, sem lugar à dúvida, que há uma correlaçăo muito grande entre o número de flores e outros parâmetros de produção. Em princípio, estes resultados parecem lógicos: entre mais flores, mais frutos; porém, considerando-se que a percentagem de flores que originam frutos é baixa (entre 3,6 e $9,2 \%$ ), os resultados não são tão claros quanto parece, à primeira vista.

É lógico pensar-se que, no caso, de existir uma correlação, esta seja maior entre o número de flores e o número de frutos verdes sendo que estes são o primeiro passo na cadeia. De fato, considerando-se que o número de flores foi estimado, como já descrito em Materiais e Métodos, e o número de frutos verdes contado, os coeficientes de correlação tanto para as árvores 1 a $6(r=0,987)$ quanto para as 7 a 10 $(r=0,951)$ são surpreendentemente altos. Isto indica duas coisas: há correlação direta entre o número de flores e frutos verdes, e a estimativa de flores foi extremamente precisa.

Os índices de correlação entre número de flores e frutos maduros são tão grandes ou maiores que os obtidos para frutos verdes $(r=0,989)^{* *}$ para as árvores 1 a $6 ;(r=$ $0,974)^{*}$ para as árvores 7 a 10 . Isto sugere que, de fato, a perda de frutos não é, ao acaso, e

TABELA 6 - Poraqueiba sericea. Média dos dados básicos de produção, incluindo, entre outros, flores, frutos verdes e maduros e peso da safra. Árvores 1 a 6, Fazenda NAF-6.

Rosa de Maio: 7 a 10 , sitio Rosa de Maio.

\begin{tabular}{|c|c|c|c|c|c|c|c|c|c|c|c|c|c|c|c|c|}
\hline \multirow{5}{*}{$\begin{array}{l}A \\
R \\
V \\
O \\
R \\
E \\
S\end{array}$} & \multicolumn{3}{|c|}{ GALHOS } & \multicolumn{3}{|c|}{ FLORES } & \multicolumn{7}{|c|}{ FRUTOS } & \multirow{2}{*}{\multicolumn{3}{|c|}{ SEMENTES }} \\
\hline & \multirow{4}{*}{ ARVORE } & \multicolumn{2}{|c|}{ INFL. } & \multirow{4}{*}{$\begin{array}{c}\text { INFL. } \\
\bar{X}\end{array}$} & \multirow{4}{*}{ TOTAL } & \multirow{4}{*}{$\begin{array}{c}\% \\
\text { FRUTI. } \\
\text { FICA } \\
\text { RAM }\end{array}$} & \multicolumn{2}{|c|}{ IMATUROS } & \multicolumn{5}{|c|}{ MADUROS } & & & \\
\hline & & \multirow{3}{*}{$\bar{x}$} & \multirow{3}{*}{ EP } & & & & \multirow{3}{*}{$\begin{array}{c}\text { POR } \\
\text { ¿ALHC } \\
\mathrm{X}\end{array}$} & \multirow{3}{*}{$\begin{array}{c}\text { Estily. } \\
\text { NA } \\
\text { AfrYore }\end{array}$} & \multirow{3}{*}{ TOTAL } & \multicolumn{3}{|c|}{ PESO } & \multirow{3}{*}{$\begin{array}{l}\text { ESTIM } \\
\text { PERD }\end{array}$} & \multicolumn{3}{|c|}{ PESO } \\
\hline & & & & & & & & & & \multicolumn{2}{|c|}{ GRAMAS } & \multirow{2}{*}{$\frac{\text { ESTIM }}{\text { KG. }}$} & & \multicolumn{2}{|c|}{ GRAMAS } & \multirow{2}{*}{$\frac{\text { ESTIM }}{\text { KG. }}$} \\
\hline & & & & & & & & & & $\bar{x}$ & EP & & & $\bar{x}$ & EP & \\
\hline 01 & 28 & 37,67 & 3,71 & 40,84 & 43.076 & 4,44 & 68,27 & 1.911 & 1.364 & 60,10 & 1,98 & 81,97 & 548 & 19,79 & 0,86 & 26,99 \\
\hline 02 & 44 & 44,00 & 4,36 & 42,69 & 82.647 & 4,21 & 79,05 & 3.478 & 2.562 & 57,42 & 1,39 & 147,11 & 916 & 19,80 & 0,55 & 50,72 \\
\hline 03 & 18 & 38,67 & 4,67 & 34,38 & 23.930 & 5,22 & 69,66 & 1.249 & 965 & 67,93 & 1,88 & 65,55 & 285 & 23,96 & 0,79 & 23,12 \\
\hline 04 & 24 & 47,00 & 3,61 & 37,24 & 42.006 & 3,64 & 63,64 & 1.527 & 1.207 & 63,72 & 1,78 & 76,91 & 320 & 27,20 & 0,85 & 32,83 \\
\hline 05 & 30 & 32,00 & 9,88 & 38,92 & 37.363 & 4,47 & 55,63 & 1.668 & 1.110 & 76,09 & 2,74 & 84,46 & 559 & 30,45 & 0,91 & 33,71 \\
\hline 06 & 14 & 27,67 & 3,39 & 33,95 & 13.151 & 4,02 & 37,77 & 528 & 407 & 76,26 & 2,16 & 31,03 & 122 & 29,98 & 0,71 & 12,20 \\
\hline 07 & 19 & 29,67 & 3,18 & 36,53 & 20.593 & 5,83 & 63,18 & 1.200 & 906 & 74,87 & 2,27 & 67,83 & 294 & 29,42 & 0,75 & 26,65 \\
\hline 08 & 28 & 23,00 & 3,22 & 35,96 & 23.158 & 6,29 & 52,00 & 1.856 & 1.416 & 69,89 & 1,99 & 126,92 & 360 & 31,28 & 1,04 & 56,80 \\
\hline 09 & 26 & 24,67 & 5,24 & 33,93 & 21.763 & 9,23 & 77,27 & 2.009 & 1.460 & 73,86 & 1,76 & 107,83 & 549 & 31,95 & 0,89 & 45,66 \\
\hline 10 & 32 & 33,00 & 5,14 & 34,96 & 36.917 & 9,05 & 104,37 & 3.339 & 2.761 & 69,08 & 1,90 & 190,73 & 579 & 26,54 & 0,87 & 73,27 \\
\hline
\end{tabular}


ocorre de uma maneira proporcional ao número de flores produzidas. Há também uma grande correlação entre o número de flores e o peso da safra. $(r=0,98)^{* *}$ para as árvores 1 a 6 ; $(r=0,951)^{*}$ para as árvores 7 a 10 . Natural mente, pode supor-se que o peso da safra é uma expressão do número de frutos maduros Se este for o caso, ao comparar o número de flores com número de frutos perdidos, deveria existir uma correlação muito alta, o que sem-
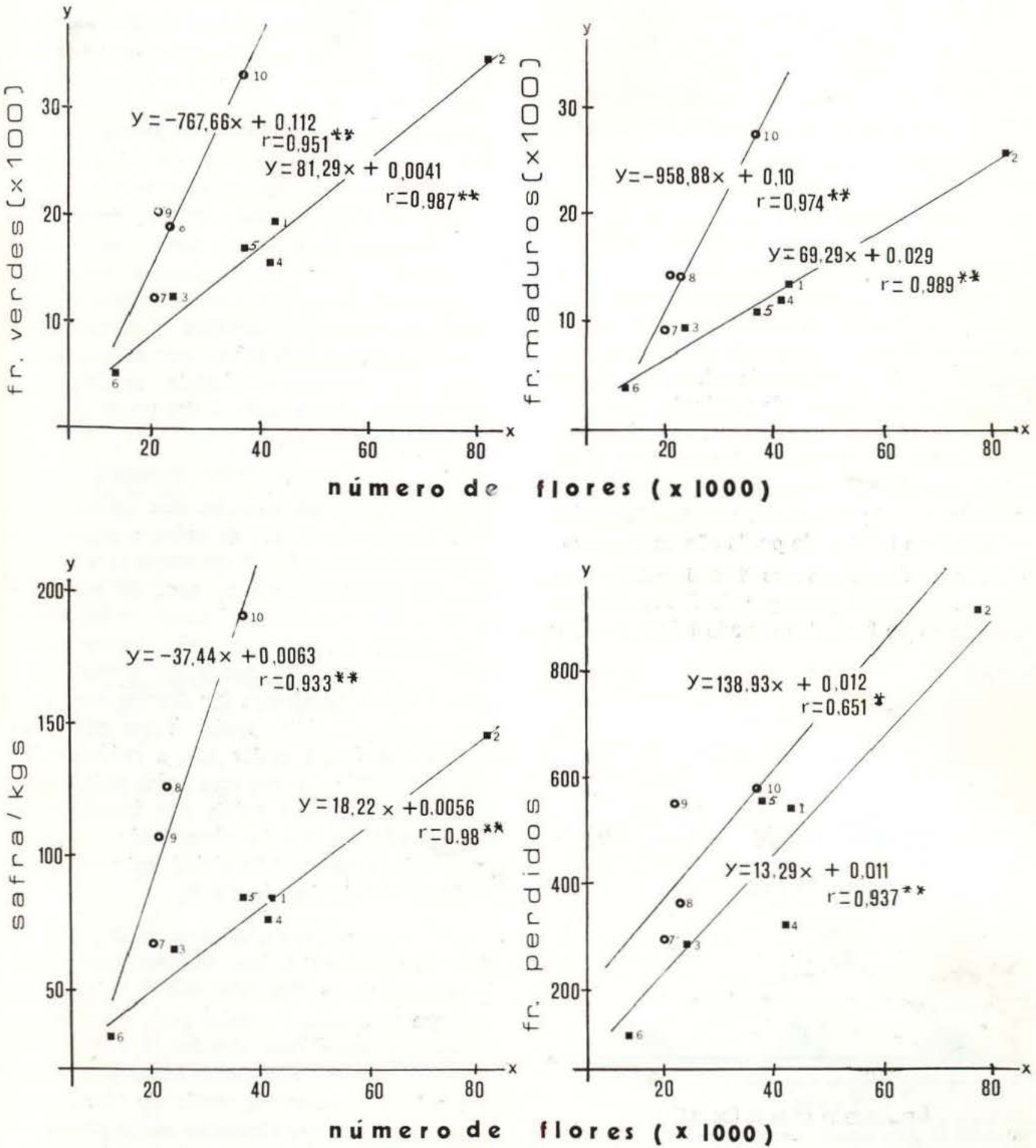

Fig. 5 - Poraqueiba seicea. Análise de regressão linear comparando número de flores $(x)$ com outros dados de produçăo $(y)$. O. Sítio Rosa de Maio; | , Fazenda NAF-6. $r=$ coeficiente de correlação entre $x$ e $y$. Os números correspondem aos rúmeros de árvores. 
pre acontece. Sugere-se, então, uma correlação entre a energia consumida em proaução de flores e em produção da massa energética da safra, mantendo certos padrões quanto ao peso individual dos frutos.

Também foi feita a regressão entre frutos verdes e maduros; como era de esperar-se, houve uma correlação $(r=0,99)^{* *}$ muito alta (Fig. 6). Estes dados são evidências adicionais de que a perda de fruto não é fortuita.

Ainda mais interessante é o fato de que não há, neste caso, diferença nenhuma entre as árvores da Fazenda NAF-6 (1 a 6) e as do Sítio Rosa de Maio ( 7 a 10). A correlação entre os frutos verdes e maduros é extremamente bem ajustada. Estes dados sugerem que ainda se a fecundação é baixa, sempre existe um excesso de frutos, formados, excesso este que é logo perdido. Porém, comparando número de flores com outros parâmetros de produção, é evidente que as árvores 7 a 10 são mais eficientes quanto à fecundação que as árvores 1 a 6 (com maior números de flores produzem maior número de frutos); sendo que uma vez formados os frutos, os índices de perda são os mesmos.

0 fato de as árvores 1 a 6 consumirem maior energia em produção de flores obtendo menor taxa de fecundação pode talvez explicar

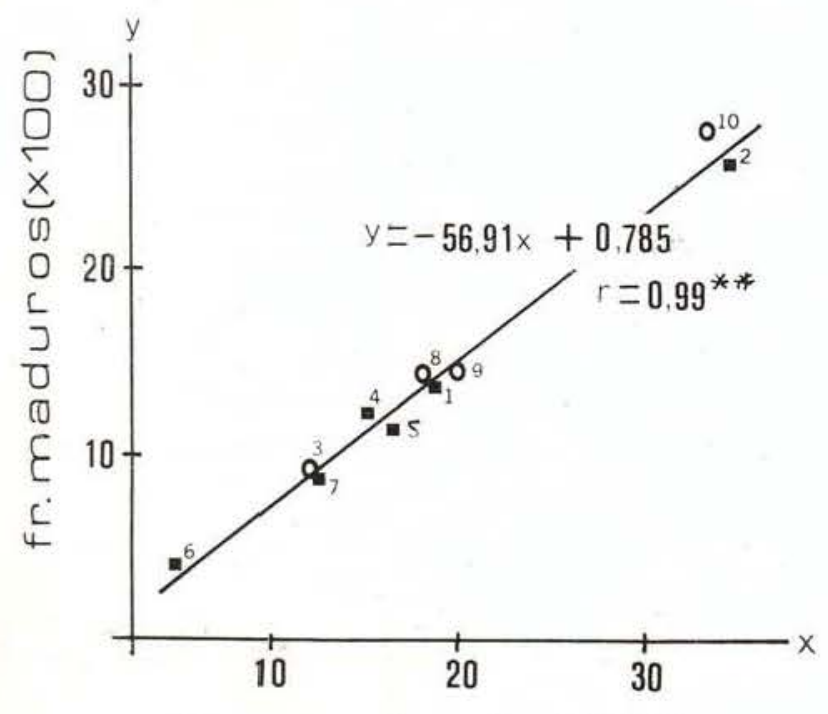

fr. verdes $(\times 100)$

Fig. 6 - Poraqueiba sericea. Regressão linear comparando números de frutos imaturos e maduros $(\mathrm{y})$. 0 , Rosa de Maio; 1 , NAF-6. porque apresentam taxa tão elevada de perda de frutos quanto às árvores mais eficientes. Pode então pensar-se que o maior consumo de energia gasto na floração diminui a energia disponivel para a produção da safra.

Como há diferença entre as percentagens de flores que frutificam ao comparar a Fazenda NAF-6 (entre 3,6 e 5,2\%) e o Sitio Rosa de Maio (5,8 e 9,2\%) pode pensar-se que as árvores da Fazenda NAF-6 estão precisando gastar muito mais energia para atrair e garantir uma taxa razoável de polinização de que as árvores do Rosa de Maio. Porém, como, além da possível diferença de densidade de polinizadores existem outros fatores tais como solo, condições microclimáticas, idade das árvores e possíveis diferenças genéticas entre "populações" é impossível, por enquanto, explicar, de maneira satisfatória, as diferenças observadas. Certamente é um ponto que merece mais pesquisa.

Quanto à produtividade propriamente dita, dois fatores foram considerados de importância: o tamanho (peso) da safra, e o peso médio dos frutos. A fig. 7 apresenta a colocação das 10 árvores quanto ao peso da safra e o peso médio dos frutos. Temos, então, quatro categorias: árvores com safra menor que a média e peso médio dos frutos menor que a média global (quadrante $\mathrm{C}$ ); árvores com safra menor que a média, porém frutos com peso médio dos frutos maior que a média global (quadrante D); árvores com safra maior que a média, porém, peso médio dos frutos menor que a média global (quadrante $\mathrm{A}$ ); e árvores com safra e peso médio global maiores que as médias globais (quadrante B).

Em termos gerais, as árvores do Rosa de Maio produziram safras maiores, com peso médio dos frutos também maior. É indiscutível que uma safra de maior peso é vantajosa. Quanto ao maior peso dos frutos, é discutíve! se isto realmente representa vantagem ou não. $\mathrm{Na}$ opinião popular, na região de Manaus, os frutos maiores tem sementes muito grandes e são poucos carnosos, com pouca polpa, sendo os frutos preferidos de tamanho médio. Outros, porém, opinam que isto é muito variável, e não pode ser generalizado. 


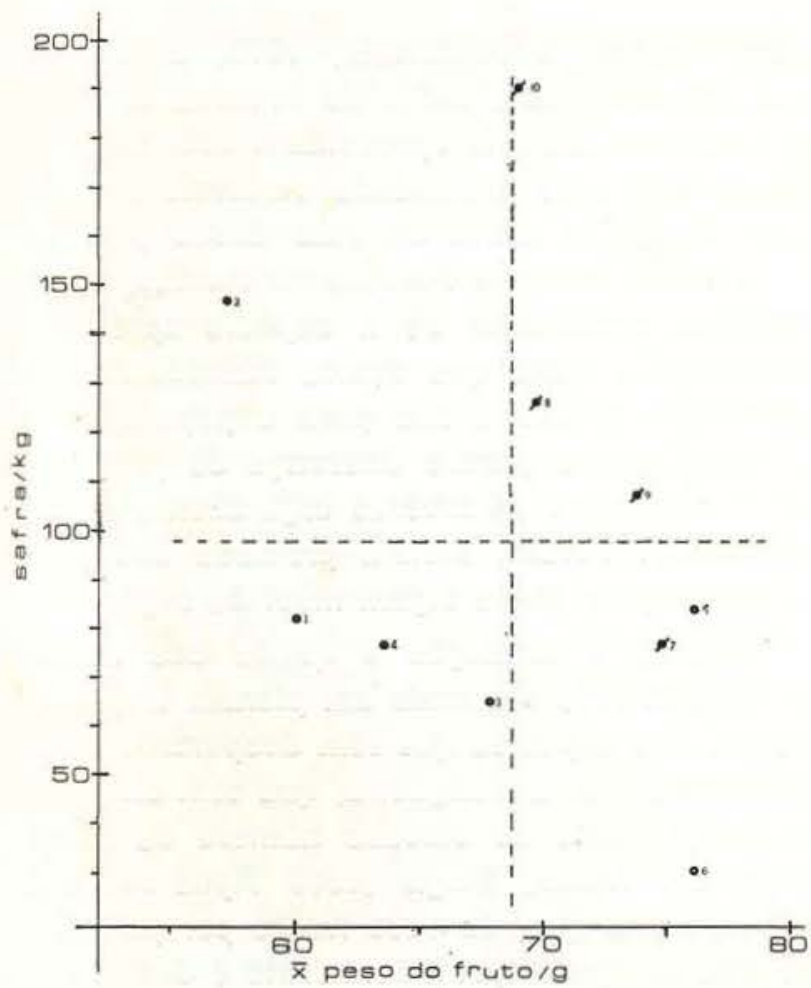

Fig. 7 - Poraqueiba sericea. Posiçăo das dez árvores com respeito ao peso da safra e média do peso dos frutos. A linha pontilhada horizontal representa a média dos pesos da safra das árvores; a linha pontilhada vertical representa a média dos pesos médios dos frutos. O, NAF-6; $\theta$, Rosa de Maio.

Na fig. 8, são apresentados os gráficos de freqüência de pesos de frutos total, polpa e semente das dez árvores e das médias das dez. Como pode observar-se, há uma grande variação quanto à distribuição e média dos frutos, polpa e sementes, não sendo possível concluir-se nada fazer quanto à afirmação de que os frutos maiores são mais carnosos. Tentouse, então, através de regressão linear, uma análise mais precisa dos dados, comparando os pesos médios dos frutos das dez árvores (x) com percentagens médias da polpa das mesmas. Os resultados são apresentados na figura 9 .

Como pode observar-se na figura, o índice de correlação entre a percentagem de polpa e o peso médio dos frutos foi relativamente baixo $(r=0,53)$, o que indica que há certa razão em afirmar que esta correlação é muito variáve! como foi anotado anteriormente. Por outro lado, o valor negativo da pendente do reta também apóía o conceito popular de que os frutos maiores são menos carnosos. Pode. ria então dizer-se que ainda, se há muita variação, a preferência popular por frutos de tamanho médio é acertada.

A problemática de floração, frutificação $c$ produtividade. é de grande interesse em fruticultura e silvicultura, sendo que até o presente, os dados são esparsos e pouco conclusivos.

Quanto à idade das árvores com relação à produtividade, algo tem sido feito para a Zona Temperada e em especial em Gimnospermas. Kramer \& Kozlowski (1972) baseados em numerosos trabalhos, anotam que, em termos ge. rais, há um acréscimo gradual de produtividade com a idade. Downs \& McQuilkin (1944 Apud. Kramer \& Kozlowski, 1972) e Wenger \& Trousdel (1958 Apud. Kramer \& Kozlowski, 1972)

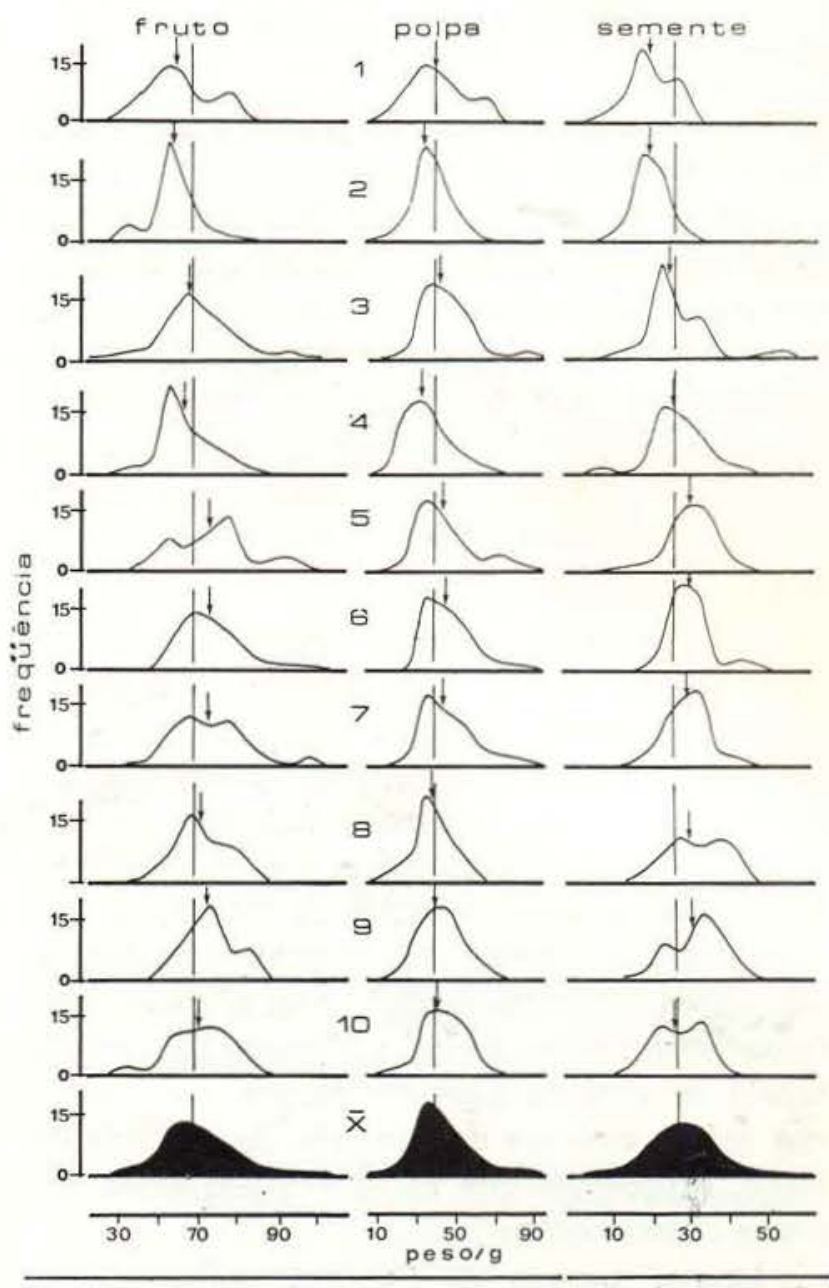

Fig. 8 - Poraqueiba sericea. Freqüências de pesos de fruto total, polpa e sementes das dez árvores e das médias das mesmas. A linha que atravessa os gráficos representa a média das médias; a seta em cada gráfico representa a média do mesmo. 


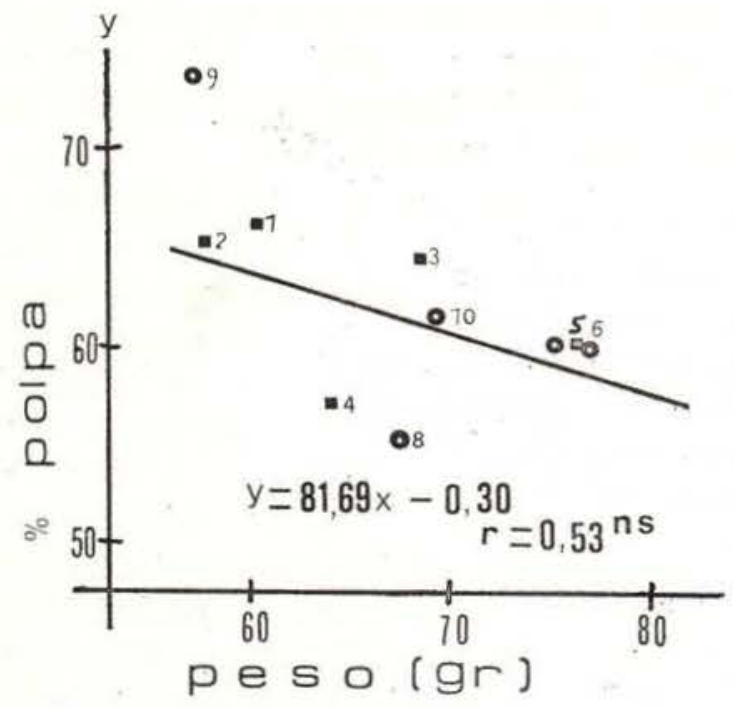

Fig. $9-$ Poraqueiba sericea. Regressão linear entre percentagem da polpa e peso médio dos frutos. NAF-6, O, Rosa de Maio.

encontraram relação muito grande entre o diâmetro do tronco e a produtividade, sendo que os primeiros anotaram que isto é válido até certo diâmetro, acima do qual há uma diminui. ção em produtividade com posterior incremento do diâmetro. Estas observações apoiam o conceito de que a capacidade de produção depende do nível de atividade metabólico e que a produção diminui nas árvores com crescimento em declínio (Baker, 1950 Apud. Kramer \& Kozlowski, 1972).

No caso de Poraqueiba sericea, não foi encontrada correlação entre diâmetro e a produtividade; porém, há certa tendência para as árvores mais velhas serem mais produtivas (as do sítio Rosa de Maio). Poraqueiba sericea inicia a frutificação com 3 a 4 anos de idade, sendo esta a segunda safra da NAF-6. É possivel então que, no futuro, as árvores da NAF-6, aumentem sua produtividade com a idade. Não foram encontrados dados a respeito da duração média de vida da espécie; porém, com bases nas safras maiores das árvores de 12 anos de idade, é provável que estas estejam ainda em pleno crescimento.

Muitas árvores de fruteiras, entre elas a macieira, a laranjeira e o cafeeiro apresentam alternância de produção com anos de produtividades alternando com anos de produção baixa (Kramer \& Kozlowski, 1972). Davis (1957
Apud Kramer \& Kozlowski, 1972) sustentam que provavelmente todas as árvores de fruto e muitas da floresta apresentam este fenômeno, porém, com intensidade variável. Em virtude de haver neste trabalho dados para só um ano de safra de Poraqueiba sericea, é impossivel determinar se a espécie apresenta alternância. Visto que ocorre individualmente para cada árvore e não para a população, é possível que a grande diferença de produção observada entre as árvores seja devida a este fenômeno. Porém, seriam precisos dez anos de dados para ter-se algum nível de segurança.

Quanto à formação e queda dos frutos, pouco tem sido estudado em plantas tropicais. Dentro das espécies que têm despertado certo interesse, está a mangueira, que tem chamado a atenção face ao elevado número de flores e poucos frutos, Singh (1960 Apud Leopold, 1964), anota que, de 6000 flores por panícula, só três ou quatro produzem fruto e deste nem todos atingem à maturidade. Situação similar tem sido notada para macadâmia e lixia (Leopold, 1964).

Há três pontos básicos a serem considerados. A causa da baixa produção de frutos pode ser devida à baixa taxa de polinização, abcisão precoce de flores e frutos novos ou nutrientes. No caso da mangueira, Spencer \& Kennard (1955) atribuíram a baixa produtividade ao período curto de receptividade das flores femininas, sendo que Simão \& Maranhão (1959) atribuiram esta baixa à polinização deficiente. No caso da macadâmia, esta espécie, além de ter produção muito baixa de frutos, também apresenta uma queda drástica de frutos novos com mais de $90 \%$ de perda dos mesmos (Urata, 1954 Apud Leopold, 1964).

Poraqueiba sericea apresenta, de fato, uma taxa de formação de frutos muito baixa. Até que ponto esta pode ser devida à pouca eficiência dos polinizadores ou à queda precoce das flores, não se chegou ainda a uma conclusão. Porém, é claro que há uma estreita relação entre o número de flores produzidas e o número de frutcs formados. Isto sugere ou que há uma divisão de recursos de polinização (polinizadores) bem ajustado dentro da "população" ou que existe um mecanismo endógeno que reduz a efetividade de fecundação seja por queda 
precoce de flores seja por outros fatores não determinados. É certamente um ponto que merece mais pesquisa.

Com relação à queda dos frutos, o fato de a safra apresentar uma relação tão grande com números de flores, sugere que este processo é controlado internamente pela planta. Muitos têm sugerido, um controle hormonal da queda precoce (Luckwill, 1953; Wright, 1956; Leopold, 1955; Leopold, 1958 entre outros). É bem provável que este seja o caso da Poraqueiba sericea. Porém, o fato de apresentar-se uma grande correlação entre plantas de uma mesma área e de existirem diferenças entre as duas áreas, sugere que também há um fator nutricional envolvido. Ainda é cedo para afirmar se este fator nutricional está correlato com a energia fotossintética disponível em forma de reserv nas plantas, ou de condições nutricionais dos solos ou uma combinação das duas.

É claro então que além dos resultados já apresentados neste trabalho para a produtividade de Poraqueiba sericea, ainda resta muito a pesquisar. Como no caso da maioria das fruteiras tropicais, pouco sabemos dos processos metabólicos envolvidos no controle da produtividade e das relações destes com fatores ambientais.

\section{AgRAdecimentos}

Agradecemos, de maneira muito especial, a revisão crítica do manuscrito, sugestões e apoio de Warwick Estevam Kerr, Maria Lúcia Absy, Hebert Otto Rogert Shubart, Angela Maria Conte Leite, Lea Maria Medeiros Carreira, assim como de todas as pessoas que colaboraram, direta ou indiretamente com este trabalho. Somos muito gratos a Osmarino Santos Monteiro que sempre colaborou no trabalho die campo, com bastante eficiência.

\section{SUMMARY}

Various aspects of the phenology, ecology and productivity of Umari (Poraqueiba sericea Tulasne) were studied. The phenological data indicated that in the vicinity of Manaus the species flowers in the dry season (June to October) with the crop reaching maturity at the height of the rainy season (January to March). Twenty one species of insects were found visiting the species, of which ten, all of them Apidae, presented significant quantities of pollen, a fact which suggests that there is no specific pollinator. The number of flowers was very high for all of ten trees studied, varying between 13000 and 82000 pen tree, with a relatively low percentage of set (between 4 and $9 \%$ ). Even though this low percentage of fruit set may be due to inefficient pollination, the surprisingly high correlation between number of flowers and other production parameters such as number of immature fruit $\left(r=0,987^{* *}\right)$, number of mature fruit $\left(r=0,989^{* *}\right)$ and weight of the crop, suggests that other factors may be playing significant roles in determining productivity (Crop). It seems that the number of flowers is intimately correlated with the energetic potential of the tree to produce a certain weight of fruit, suggesting endogenous control of number of fruits formed and aborted in such a way as to maintain a certain number and weight of fruit reaching maturity.

\section{BIBLIOGRAFIA}

Altman, R.F.A.; Olivetra, P.C. \& Silva, E.O.G.E. 1965a- A composição química do fruto Umary (Poraqueiba paraensis Ducke) e ( $P$. sericea Tul.) Manaus, INPA Publ. avulsa, (4): 5p.

Altman, R.F.A.; SILVA, L.M. \& Neves, S.M.

1965b- O óleo do Umari. Publ. do Instituto Nacio. nal de Pesquisas da Amazônia (8): 1-16p Química.

Carvalho, Maryan C.

1971 - O pólen em plantas da Amazônia. Gêneros Poraqueiba Aubl. e Emmotum (incacinaceae) Desv. Bol. do M. P. E. Goeldi, N. S. Botânica, (42): 1-4p.

Cavalcante, P.B.

1976 - Frutas Comestiveis da Amazônia, 3 ed. Belém, INPA. $166 \mathrm{p}$.

Cavalcante, P.B. \& Carvalho, M.C.

1971 - Poraqueiba (Icacinaceae) na Amazônia Bol. do Museu Paraense E. Goeldi. N. S. Botâ. nica, (39): 1-10p

Clement, C.R.; Kerr, W.E.; Weber, H.; Freitas, E.;

Arkcoll, D.E.; RANzani, G. \& Pahlen, E. von Der

1977 - Ecologia e Fruticultura da Amazônia. In Seminário de Fruticultura, Manaus, (Mimeografado). 20p. (no prelo).

ENGLER, A.

1872 - "Olacinae, Icacineae, Zygophylleae". In: Martius, C.F.P. von. Flora Brasiliensis, Monachii, Frid. Fleischer, 15 v. (pt. 2), v. 12p. 47-49, est. 10 .

ERDTMAN, G.

1960 - The acetolysis method: - a revised description. Sv. Bot. Tidskr. Lund. 54 (4): 561564 . 
FonseCA, E.T.

1954 - Frutas do Brasil. Rio de Janeiro, Inst. Nac. Livro 281p.

GoNdIM, C.J.E.

1978 - Alguns Aspectos da Biologia Reprodutiva do Guaraná (Paullinia cupana var sorbilis (Martius) Ducke) - Sapindaceae. Tese de Mestrado. INPA. Manaus, 83p.

HOWARD, A.

1942 - Studies of the Icacinaceae IV. Consideration of the New World Genera 92p.

KerR, W.E.; Clement, C.R. \& Silva Filho, D.F.

1980 - Práticas de Conseqüências Genéticas que Possibilitavam aos Indios da Amazônia uma Melhor Adaptação às Condições Ecológicas da Região. Acta Amazonica, 10 (2):

KRAMER, P. \& KOZLOWSKI, T.

1972 - Fisiologia das Árvores. Lisboa, Fundação Calouste Gulbenkian. 745p

Le Cointe, $P$.

1947 - Amazônia brasileira III. Árvores e plantas úteis (indígenas e aclimatadas), 2. ed. $\mathrm{S}$. Paulo ED. Nacional. 506p.

LEOPOLD, A.C.

1955 - Auxins and Plant Growth, Univ, Calif. Press, Berkeley, 354p.

1958 - Auxin uses in the Control of flowering and fruiting. Ann Rev. Plant Physiol., 9: 281-310.

1964 - Plant Growth and Development. New York, McGraw - Hill.
LUCKWILL, L.C.

1953 - Studies of Fruit Development in relation to Plant Hormone II. The Effect of Naphthalene Acetic Acid on fruit Set and Fruit Development in Apples. J. Hort Sci. 28: 25-40.

PAHLEN, EVA VON DER

1978 - Fruteiras para a Amazônia. In Introduçäo à Horticultura e Fruticultura no Amazonas. SUFRAMA.

PEsce, C

1941 - Oleaginosas da Amazônia. Belém, R. Vete. rinária (2): 1-128p.

Prance, G.T. \& SILVA, M.

1975 - Árvores de Manaus. Manaus, INPA. 312p.

RIBEIRO, M.N.G.

1977 - Boletim Meteorológico Mensal. Instituto Nacional de Pesquisas da Amazônia. Setor de Meteorologia, Manaus, $14 p$.

SIMÃo, S. \& MARANHÃo, C.Z.

1959 - Os Insetos Como Agentes Polinizadores da Mangueira. Anais da Escola Superior de Agricultura "Luiz Queiroz", 16: 299-309

SPENCER, L.C. \& KenNARD, W.C.

1955 - Studies on Mango (Mangifera indica L.). Fruit Set in Puerto Rico. Trop. Agric. (London) 32: 323-330.

WRIGHT, S.T.C,

1956 - Studies of Fruit Development in Relation to Plant Hormones III. J. Hort. Sci. 31: 196-211.

(Aceito para publicação em $03 / 12 / 79$ ) 